\title{
Risky Sexual Behaviour Among Married and Cohabiting Women and its Implication for Sexually Transmitted Infections in Mahikeng, South Africa
}

\author{
Godswill N. Osuafor ${ }^{1} \cdot$ Natal Ayiga ${ }^{1}$
}

Published online: 21 May 2016

(C) The Author(s) 2016. This article is published with open access at Springerlink.com

\begin{abstract}
Risky sexual behaviour continues to be the main means through which sexually transmitted infections (STIs) and HIV are spread in South Africa. However few studies have assessed risky sexual behaviour among married and cohabiting women in this high HIV prevalence country. The aim of this study was therefore to assess the prevalence and identify the predictors of risky sexual behaviour among married and cohabiting women in Mahikeng Local Municipality where HIV is generalized. The study used cross-sectional mixed methods data obtained from 568 women responding to a survey and 33 women participating in in-depth interviews in 2012. All the women were aged 18-49 years, married or cohabiting and were residing in rural and urban areas of Mahikeng Local Municipality at the time of the study. The data was analyzed by the use of the Chi square statistic and a parsimonious binary logistic regression model, and the thematic content analysis method. The study found that 4 in 10 of the women experienced risky sexual behaviour, which was significantly predicted by being in marriage or cohabitation for $<5$ years, having a partner working in agriculture, government and mining sectors, having sex to achieve motherhood, having the perception by the women that they were unlikely to contract STIs, having the belief that partners have the right to use force to obtain sex and having partners who were unwilling to use condoms. All the above predictors were exacerbated by culturally sanctioned gender inequality and structural factors. The findings suggest that risky sexual behaviour is prevalent among married and cohabiting women in the study area which has serious implication for the marital transmission of STIs and HIV. We suggest interventions that enhance gender equality in sexual decisions and initiatives that encourage men to change their sexual beliefs and values.
\end{abstract}

Godswill N. Osuafor gosuafor@gmail.com

1 Population and Health Research Focus Area, Faculty of Human and Social Sciences, North West University (Mafikeng Campus), Mahikeng, South Africa 
Keywords Sexual behaviour · STIs and HIV · Marriage and cohabitation · South Africa

\section{Introduction}

Risky sexual behaviours which are defined as behaviours that increase the risk of transmission of sexually transmitted infections (STIs) and HIV continue to be wide spread in sub-Saharan Africa and it explains why HIV is now endemic in this region (Chialepeh and Susuman 2015). These behaviours include early age at sexual debut, having multiple sexual partners, unprotected sex with strangers, sex with partners whose STI status is unknown and when one or one's sexual partner has a STI (Agarwal et al. 2013). In South Africa, where the HIV pandemic is large, risky sexual behaviour by young unmarried adults is common (Van et al. 2012). However, little is known of the same behaviours among married and cohabiting women. This study is therefore an attempt to assess the prevalence and identify the predictors of risky sexual behaviour among married and cohabiting adults in a predominantly rural area in South Africa.

Assessing the prevalence and predictors of risky sexual behaviour became an area of public health importance in the advent of HIV/AIDS. Most of the assessment studies were focused on unmarried youth because of the high level of sexual activity in this group. A study by Shisana (2005) in South Africa attributed the high prevalence of HIV in women to risky sexual behaviour. Similar studies in Botswana (Langeni 2007) and Zimbabwe (Gregson et al. 1995) suggested that risky sexual behaviour among married and cohabiting women occurs because of the belief that they are protected against STIs. Other studies on risky sexual behaviour in Rwanda and Zambia also revealed that over half of new HIV infections (Dunkle et al. 2008) and most unprotected sexual acts by HIV infected persons in sero-discordant sexual relationship in Kenya, Uganda and Malawi occur in marriage (Anand et al. 2009). Another set of studies by Da Walque (2007) in five African countries and Shannon et al. (2012) in Botswana and Swaziland found that married couples engage in unprotected sex with other sexual partners. It is therefore evident that the sexual behaviour of married and cohabiting women could increase their susceptibility to STIs. The studies also suggest that marriage may not protect women against STIs as previously thought, which makes this study particularly relevant because it was conducted in a high HIV prevalence setting.

Risky sexual behaviour is influenced by many factors. These include culture that impedes equality between men and women on sexual decisions (Browne et al. 2012). A study in South Africa found that men have more power in sexual matters in marriage than women (Hargreaves et al. 2009). The power is rooted in cultural norms and values that place married women subordinate to men because of the belief that bride price, locally known as "lobola", gives men unlimited sexual rights over their wives (Scott 2010). As a result, efforts to avoid risky sex by women may be construed by men as infringement on their conjugal rights (Adamczyk and Greif 2011). The unequal power over sex is also displayed by men's unwillingness to practice safe sex (Falola and Heaton 2007) and demands in that regard by women is often portrayed as a sign of mistrust or infidelity (Ayiga 2012). 
Risky sexual behaviour can also be influenced by structural factors. One of these is a lack of or low level of education, which deprives women of knowledge and resources that can enable them to adopt safe sex practices. Higher education provides knowledge and helps women to adopt attitudes and behaviours that enable them to revoke cultural norms and values that promote inequality in marriage (Kroska and Elman 2009). It also empowers women by increasing opportunities for employment and incomes that enable them to adopt behaviours that enhance gender equality in sexual matters (Haberland 2015). However, one epidemiological study by Hargreaves and Glynn (2002) found that people with higher education are more likely to engage in risky sexual behaviours, which was attributed to higher incomes that can afford risky lifestyles (Tenkorang et al. 2011). Another structural factor that increases risky sexual behaviour is poverty, which makes women remain dependant on men and prevents them from adopting safer sex measures (Dodoo and Frost 2008). It also prevents women from challenging the risky sexual behaviours of their partners because of their dependence (Miller et al. 2011). On the other hand, economic independence of women increases the power they have in marital and sexual decisions (Osuafor and Mturi 2014), which can protect them from engaging in risky sexual behaviours and exposure to STIs.

Risky sexual behaviours can also be influenced by individual level factors. Key among these is the reason for engaging in sexual activities in marriage (Wusu and Isiugo-Abanihe 2010). In South Africa as in other sub-Saharan African countries, motherhood is the most important reason for getting married. As a result, women who do not have children when married can go to any length to achieve motherhood (Dyer et al. 2004). Motherhood also provides women with status and a sense of acceptance and stability in marriage. A study in South Africa, found that many women who get pregnant before marriage do so to prove their motherhood to their prospective future husbands so as to gain acceptance and approval (White et al. 1990). Additionally, women engage in unprotected sex to show love and view such sex as an important means of increasing their connectedness with their partners (Jones et al. 2013).

Although much knowledge exists in South Africa on risky sexual behaviour among young unmarried adults, little is known about risky sexual behaviours among married and cohabiting women. The paucity of knowledge on this behaviour among married and cohabiting women is critical in preventing marital transmission of STIs and HIV in South Africa, where HIV continues to be a daunting and large pandemic. This study therefore aimed at assessing the prevalence of and identifying the main predictors of risky sexual behaviour among married and cohabiting women in Mahikeng Local Municipality. The findings of the study could assist in developing interventions that increase safer sexual behaviours and reduce the risk of marital transmission of STIs and HIV among married and cohabiting women.

\section{Subjects and Methods}

\section{Study Design and Setting}

The study used a cross-sectional design and employed quantitative and qualitative methods to collect data. In the quantitative method we used a pretested structured 
questionnaire to collect data on demographic, socioeconomic and sexual variables. The qualitative data was collected by the use of the in-depth interview method in which an interview guide comprising open ended questions and probes was used to collect data on perceptions and attitudes on risky sexual behaviour. The survey was conducted in both rural and urban wards of Mahikeng Local Municipality in 2012.

\section{Sampling}

The list of the enumeration areas developed for the 2011 census by Statistics South Africa was used to select the enumeration areas (EAs) from which the sample for the study was drawn. The two stage sample design was used to select participants for the study. The first stage comprised the selection of EAs using probability proportional to the size of rural and urban households. From the selected EAs, 600 households had women who met the inclusion criteria which were being 18-49 years old, being currently married or cohabiting and usually residing in the selected households. A total of 568 women who completed the questionnaire were included in the analysis. The in-depth interview included 33 women who were purposively selected based on their willingness to share information on their sexual behaviour.

\section{Measures}

The dependent variable was sexual behaviour which was binary in nature and was coded " 1 " if a woman ever had a risky sexual behaviour in her status as married or cohabiting and " 0 " if otherwise. The predictor variables included in the analysis were demographic, social and sexual characteristics of the women. Demographic characteristics were age categorized in 5-year age intervals and duration of marriage or cohabitation categorized as $<5,5-9$ and 10 years or more. Social characteristics included place of residence categorized as rural and urban; highest level of education categorized as no education, primary, secondary and tertiary education and occupation of respondent categorized as unemployed, trading, government sector, teacher, student and domestic worker. Others were religion categorized as Catholic, Methodist, Pentecostal, SDA and other religions; home language which was used as a proxy for culture and categorized as Setswana, Afrikaans, IsiXhosa, Sesotho and Zulu; and partner's occupation categorized as unemployed, trading, government sector, teacher, miner and casual labour.

Data on sexual characteristics included perceived risk of contracting STIs categorized as likely, unlikely and none; level of knowledge of safe sex methods categorized as good, moderate, low and none; and reasons for sex categorized as pleasure and childbearing. Knowledge that sexual behaviour can affect one's health categorized as no, yes and don't know; belief that partners have a right to use force to obtain sex categorized as yes and no; partner's willingness to use condoms categorized as no and yes; and spousal communication on sexual matters categorized as yes and no were also analysed. 


\section{Methods of Analysis}

Data were analysed using three stages. The first stage described the profile of the study subjects. The second step used the Chi square statistic to assess the association between risky sexual behaviour and the demographic, social and sexual characteristics of women excluding missing cases. The Chi square estimator used was of the form: $\chi^{2}=\sum\left(\mathrm{f}_{0}-\mathrm{f}_{\mathrm{e}}\right)^{2} / \mathrm{f}_{\mathrm{e}}$. We concluded that sexual behaviour of the women and demographic, social and sexual variables were statistically dependent if the $p$ value was $<0.05$.

The third stage was the multivariate analysis which was used to identify variables that predicted risky sexual behaviour. All variables in the study were entered in the model and a parsimonious binary logistic regression model was used to identify and report the variables that significantly predicted risky sexual behaviour. The logistic regression model used was of the form: $y=\log _{e} \frac{P_{i}}{1-P_{I}}$. The choice of the model was informed by the dichotomous nature of the dependent variable which took the value " 1 " if the women ever had risky sexual behaviour and " 0 " if otherwise, which satisfied the condition for binary logistic model (Elisa and Wang 1992). The parametric estimator used for the interpretation of the result was the exponentiated coefficients $\left(\beta^{2}\right)$ (Odds Ratio). A variable was declared a significant predictor of risky sexual behaviour if the $p$ value associated with the Odds Ratio was $<0.05$.

The in-depth data was first transcribed in Setswana which is the dominant language in the study area and then translated into English. The analysis was done by the use of the thematic content analysis method. The transcribed information was organized under four broad themes namely, sexual behaviour; culture and sexual behaviour; structural factors and sexual behaviour; and individual level factors and sexual behaviour. Topical statements and phrases on the themes were used to illustrate the views and perceptions of the study subjects.

\section{Results}

\section{The Profile of the Study Subjects}

Table 1 presents the profile of the study subjects showing that the median age of the women was 34 years and the age pattern was the normal bell-shaped curve with a peak at age group 30-34. The median duration of marriage or cohabitation was 9 years and slightly more than one-third of the women have been married or cohabitating for $<5$ years. Nearly 8 in 10 of the women resided in rural areas and the majority $(31.5 \%)$ followed by just over one-fifth had primary and secondary education respectively. Nearly 3 in 10 were unemployed and 2 in 10 worked in the government sector. Distribution of the women by religion showed that the majority were Pentecostal followed by Methodist, SDA and Catholic while Setswana was the dominant language group. Regarding the partners of the women, nearly one quarter worked in trade, one-third worked in government and $12 \%$ worked in the mining sector. 
Table 1 Percentage distribution of women by sociodemographic characteristics

\begin{tabular}{lcc}
\hline Characteristics & Number & $\%$ \\
\hline Age groups & & \\
$<25$ & 63 & 11. \\
$25-29$ & 108 & 19.0 \\
$30-34$ & 114 & 20. \\
$35-39$ & 120 & 21. \\
$40-44$ & 89 & 15.7 \\
$45-49$ & 74 & 13.0
\end{tabular}

Duration of union in years

$<5$

218

38.4

5-9

158

27.8

10 or more

192

33.8

Place of residence

Rural

Urban

123

21.6

Highest level of education

No education

Primary

179

31.5

Secondary

156

27.5

Tertiary

121

21.3

Occupation of respondent

Unemployed

165

Trading

80

14.1

Government sector

134

23.6

Teaching

10.4

Student

8.3

Domestic worker

83

14.6

Religious affiliation

Catholic

Methodist

Pentecostal

146

37.5

SDA

213

16.7

Other religions

Home language group

Setswana

Afrikaans

IsiXhosa

Sesotho

Zulu

Partner occupation

Unemployed

Agriculture

Trading

Government sector
24.8 
Table 1 continued

\begin{tabular}{|c|c|c|}
\hline Characteristics & Number & $\%$ \\
\hline Teaching & 63 & 11.1 \\
\hline Miner & 62 & 10.9 \\
\hline Casual labour & 46 & 8.1 \\
\hline \multicolumn{3}{|c|}{ Perception of risk of contracting STIs } \\
\hline Unlikely & 265 & 49.0 \\
\hline Likely & 120 & 22.2 \\
\hline None & 156 & 28.8 \\
\hline Not stated & 27 & - \\
\hline \multicolumn{3}{|c|}{ Level of knowledge of safe sex } \\
\hline Comprehensive & 186 & 34.1 \\
\hline Moderate & 330 & 60.4 \\
\hline Low & 22 & 4.0 \\
\hline Not at all & 8 & 1.5 \\
\hline Not stated & 22 & - \\
\hline \multicolumn{3}{|c|}{ Reasons for risky sexual behaviour } \\
\hline Pleasure & 78 & 28.7 \\
\hline Childbearing & 393 & 71.3 \\
\hline Not stated & 52 & - \\
\hline \multicolumn{3}{|c|}{ Knowledge that sexual behaviour can affect health } \\
\hline Not important & 284 & 50.0 \\
\hline Important & 264 & 46.5 \\
\hline Don't know & 20 & 3.5 \\
\hline \multicolumn{3}{|c|}{ Belief that partner has rights to use force to obtain sex } \\
\hline No & 421 & 76.3 \\
\hline Yes & 131 & 23.7 \\
\hline Not stated & 16 & - \\
\hline \multicolumn{3}{|c|}{ Partner's willingness to use condoms } \\
\hline No & 185 & 33.5 \\
\hline Yes & 367 & 66.5 \\
\hline Not stated & 16 & - \\
\hline \multicolumn{3}{|c|}{ Spousal communication about sex } \\
\hline Yes & 352 & 63.8 \\
\hline No & 200 & 36.2 \\
\hline Not stated & 16 & - \\
\hline Total & 568 & 100.0 \\
\hline
\end{tabular}

Table 1 also presents the distribution of the women by their sexual characteristics showing that nearly half of the women and $30 \%$ of the women perceived that they were unlikely and will not contract STIs respectively. More than 6 in 10 had moderate and over one-third had good knowledge of safe sex methods, while 8 in 10 said childbearing was the main reason for engaging in sex. Half of the women knew that their sexual behaviour can affect their health and nearly 8 in 10 said their 
partners have no right to use force to obtain sex. Another 7 in 10 of the women said their partners were willing to use condoms and 6 in 10 said they communicated on sexual matters with their partners.

\section{Distribution of Women by Sexual Behaviour}

Nearly $42 \%$ of the women have experienced a risky sexual behaviour. This is corroborated by the perception of some of the women in the in-depth interviews. Although the majority of the women said that they did not have risky sexual behaviour, the possibility of engaging in risky sexual activities with their partners is always there. Some of the women said they could have engaged in risky sexual behaviour because of fear of their partner's reaction especially if they refuse to have sex because of being infected with a STI while their partner is apparently healthy. One such participant said":

The only reason is fear of violence, judgment and rejection by my husband. In addition, going to the clinic alone for treatment assumes that you are irresponsible by having unprotected sex with many partners when you are married. It is difficult to convince your husband to go and test and receive treatment when you know you have an infection and he does not show any sign. (Rural woman, age 28, married for 10 years).

In line with the fear of the outcome of avoiding risky sexual behaviour, one of the participants said:

The problem is that men do not take no for an answer. We do have fears; it is just that when you say no, they think you are saying yes. It is sometimes difficult to give reasons because you don't know what the result could be. (Rural woman, aged 28, cohabiting for 6 years).

However, some women argued that there is no need to engage in protected sex with their partners. This is mainly because the source of STIs is usually the man and not the woman. The view is that married women are mostly faithful. This view was illustrated by one participant who said:

Apparently men are the ones who bring STIs in a relationship, because most women do not cheat. I don't see the reason why I should have HIV if it is not my husband who brought it. He is the first and only man I have ever slept with. If I have STIs it comes from him. (Urban woman, aged 31, cohabiting for 6 years).

Further evidence of risky sexual behaviour was observed among those who said they would still have sex because they have no reason to give for avoiding risky sex, knowing that they are faithful to their partner. A participant said:

I do not want to fight with him, if I lie to him that I am sick or tired today, what will be my reason tomorrow. I am not sure if he is cheating, but men who drink and do not respect their partners are not reliable. (Rural woman, aged 36, married for 7 years). 


\section{Differentials in Risky Sexual Behaviour}

Table 2 presents the differentials in risky sexual behaviour by socio-demographic and sexual characteristics of the women. The table shows that risky sexual behaviour was significantly more prevalent among rural women and it decreased monotonically as the level of education increased, with 6 in 10 women with no education compared to only 2 in 10 with tertiary education saying they have had risky sexual acts. Having a risky sexual behaviour was also more prevalent among unemployed women, followed by women working in trade and domestic work. Table 2 also shows that risky sexual behaviour was more prevalent among women whose partners worked in agriculture, government and the mining sector.

Furthermore, Table 2 shows that risky sexual behaviour was more prevalent among women who perceived they were not at risk of contracting STIs; had no knowledge or low level of knowledge on safe sex methods; and engaged in sex mostly for childbearing. Additionally, risky sexual behaviour was more common among women who believed their partners have the right to use force to obtain sex; their partners were unwilling to use condoms; and among women who did not communicate about sex with their partners.

The results of in-depth interviews on risky sexual behavior were mixed because of the perception by some women that being in stable unions protects them from STIs and that some STIs take a very long time to show symptoms. Some women attributed marital protection against STIs to faithfulness of their partners. This has been expressed by the following statement:

My husband does not show me any signs to make me not to trust him. So there could be no way for me to know that he has STIs. Besides, some STIs such as HIV have no signs. (Urban woman, aged 34, married for 10 years).

However, some women were concerned that they could have engaged in risk sexual behavior. They reasoned that their partners work far from home and are away for a long time. Such men could engage in risky sexual behaviour and put their wives at risk of STIs when they returned home. Some of the women illustrated their concerns in the following statements:

I see myself at risk as men are not trustworthy. My husband is working outside Mahikeng and could engage in risky sexual behaviour at his work place. (Rural woman, aged 35, married for 8 years).

Yes I am at risk as men are not trustworthy, you will never know what they do when they are out there. (Rural woman, aged 31, married for 10 years).

The women also said the reason for sex could expose them to STIs through risky sexual behaviour. Women who have sex to bear children were more likely to have risky sexual behaviour than those who have sex for pleasure. This was illustrated by the following statement:

We women sometimes become desperate when you want to have a child but it refuses to come. You will find that you will have sex under any conditions not 
Table 2 Percentage of women who reported risky sexual behaviour by socio-demographic characteristics

\begin{tabular}{lll}
\hline Characteristics & Number & $\begin{array}{l}\% \text { of women in risky } \\
\text { sexual behavior }\end{array}$ \\
\hline
\end{tabular}

\begin{tabular}{lrl}
\hline Age groups & & \\
$<25$ & 63 & 42.6 \\
$25-29$ & 108 & 44.2 \\
$30-34$ & 114 & 42.5 \\
$35-39$ & 120 & 44.3 \\
$40-44$ & 89 & 34.9 \\
$45-49$ & 74 & 39.7
\end{tabular}

Duration of union in years

$<$

5-9

218

45.3

0.369

10 or more

158

40.5

Place of residence

$\begin{array}{lll}\text { Rural } & 445 & 46.1 \\ \text { Urban } & 123 & 25.4\end{array}$

Highest level of education

No education $\quad 112$

66.4

0.001

Primary

179

45.3

Secondary

156

33.1

Tertiary

121

24.4

Occupation of respondent

Unemployed 165

61.2

0.001

Trading

80

45.2

Government sector 134

29.2

Teaching

30.5

Student

59

20.5

Domestic worker

47

38.3

Religious affiliation

Catholic

47.8

Methodist

72

32.4

Pentecostal

146

45.5

SDA

213

38.0

Other religions

42

51.2

Home language group

\begin{tabular}{lrrr} 
Setswana & 376 & 39.5 & 0.288 \\
Afrikaans & 21 & 33.3 & \\
IsiXhosa & 50 & 49.0 \\
Sesotho & 74 & 43.1 \\
Zulu & 47 & 53.3 \\
Total & 568 & 41.7 \\
\hline
\end{tabular}


Table 2 continued

\begin{tabular}{|c|c|c|c|}
\hline Characteristics & Number & $\begin{array}{l}\% \text { of women in risky } \\
\text { sexual behavior }\end{array}$ & $p$ value \\
\hline \multicolumn{4}{|l|}{ Partner occupation } \\
\hline Unemployed & 40 & 32.5 & \multirow[t]{7}{*}{0.007} \\
\hline Agriculture & 24 & 75.0 & \\
\hline Trading & 141 & 39.0 & \\
\hline Government sector & 192 & 38.4 & \\
\hline Teaching & 63 & 37.7 & \\
\hline Miner & 62 & 54.1 & \\
\hline Casual labour & 46 & 42.2 & \\
\hline \multicolumn{4}{|c|}{ Perception of risk of contracting STIs } \\
\hline Unlikely & 265 & 33.2 & \multirow[t]{3}{*}{0.001} \\
\hline Likely & 120 & 35.0 & \\
\hline None & 156 & 58.3 & \\
\hline \multicolumn{4}{|c|}{ Level of knowledge of safe sex } \\
\hline Comprehensive & 186 & 39.2 & \multirow[t]{4}{*}{0.007} \\
\hline Moderate & 330 & 40.3 & \\
\hline Low & 22 & 45.5 & \\
\hline Not at all & 8 & 100.0 & \\
\hline \multicolumn{4}{|c|}{ Reasons for risky sexual behaviour } \\
\hline Pleasure & 78 & 33.5 & \multirow[t]{2}{*}{0.015} \\
\hline Childbearing & 393 & 44.8 & \\
\hline \multicolumn{4}{|c|}{ Knowledge that sexual behaviour can affect health } \\
\hline Not important & 284 & 45.4 & \multirow[t]{3}{*}{0.060} \\
\hline Important & 264 & 37.5 & \\
\hline Don't know & 20 & 32.1 & \\
\hline \multicolumn{4}{|c|}{ Belief that partner has rights to use force to obtain sex } \\
\hline No & 421 & 35.6 & \multirow[t]{2}{*}{0.001} \\
\hline Yes & 131 & 61.1 & \\
\hline \multicolumn{4}{|c|}{ Partner's willingness to use condoms } \\
\hline No & 185 & 54.1 & \multirow[t]{2}{*}{0.001} \\
\hline Yes & 367 & 35.4 & \\
\hline \multicolumn{4}{|c|}{ Spousal communication about sex } \\
\hline Yes & 352 & 30.7 & \multirow[t]{3}{*}{0.001} \\
\hline No & 200 & 61.0 & \\
\hline Total & 568 & 41.7 & \\
\hline
\end{tabular}

Note: In some variables the total number of cases does not add to 568 because missing cases were omitted in the analysis

minding STIs with the hope that you will get that child. (Urban woman, aged 30, married for 4 years).

Regarding partners' right to use force to obtain sex, women who perceived that partners have the right to use force to obtain sex have ever engaged in sexually risky behaviour. This was attributed to the cultural rights men enjoy on matters of 
sexuality with their wives due to having paid bride price. One of the participants noted:

According to the society you are not supposed to refuse sex for your husband and my culture does not support me as he is my husband who has fulfilled cultural requirements for marriage (Rural woman, aged 44, married for over 10 years).

The younger generation similarly expressed the same view on the tenacity of culture in promoting the conjugal rights of men to have sex above that of women.

When he wants it (sex) nobody will stop him even if it is red (menstruating) he does not care. I know it belongs to him, he has rights to have it anytime, unless I share him with somebody. So I think I have no right to deny sex to him (Rural woman, age 28, married for 9 years).

Women also considered communication on sexual matters with their partners as important in reducing risky sexual behaviour as communication creates mutual empathy and trust. The result from the in-depth interviews revealed that women's sexual rights could be improved through communication:

Women must stop being insecure and know their rights and engage their partners through talking openly on sexual matters for them to respect the sexual rights of women (urban woman, aged 40, married for over 10 years).

\section{Predictors of Risky Sexual Behaviour}

In Table 3 the parsimonious result of the binary logistic regression model is presented. The model identified the significant predictors of risky sexual behaviour by the women showing that the likelihood of risky sexual behaviour decreased with the duration of marriage. Only women who have been in marriage or cohabitation for $<5$ years were at $(\mathrm{OR}=1.71, \mathrm{CI}=1.04-2.83)$ an elevated risk of risky sexual behaviour. Partner's occupation was also found to be a significant predictor of risky sexual behaviour. The women were $6.04(\mathrm{CI}=1.68-21.69), 2.36(\mathrm{CI}=1.00-2.26)$ and $2.76(\mathrm{CI}=1.03-7.42)$ times significantly more likely to have engaged in a risky sexual behavior if their partners worked in agriculture, government and mining sectors respectively. Furthermore, Table 3 shows that women who perceived they were unlikely to contract STIs and had sex mainly because they wanted to bear children, were $2.85(\mathrm{CI}=1.74-4.67)$ and $1.72(\mathrm{CI}=1.10-2.72)$ times significantly more likely to have engaged in a risky sexual act. Additionally, the women were significantly more likely to have engaged in a risky sexual act if they believed their partners have the right to use force to obtain sex $(\mathrm{OR}=1.90, \mathrm{CI}=1.25-2.90)$ and their partners were unwilling to use condoms $(\mathrm{OR}=1.55, \mathrm{CI}=0.36-0.56)$.

Conversely, the result of the binary logistic regression model shows that the women were significantly less likely to have engaged in a risky sexual act if they had tertiary $(\mathrm{OR}=0.14, \quad \mathrm{CI}=0.05-0.34), \quad$ secondary $\quad(\mathrm{OR}=0.27$, $\mathrm{CI}=0.14-0.51)$ and primary education $(\mathrm{OR}=0.38, \mathrm{CI}=0.22-0.67)$; and were students at the time of the study $(\mathrm{OR}=0.40, \mathrm{CI}=0.16-0.099)$. Women who knew 
Table 3 Parsimonious logistic regression model showing odds ratios predicting risky sexual behaviour of women
* Significant at 0.05 level;

** significant at 0.01 level;

**** significant at 0.001 ;

$* * * *$ significant at $0.0001 ; 1.00$

reference category and $C I$

confidence interval

Predictor variables
Duration of union in years
$<5$

Odds ratio

CI

\begin{tabular}{|c|c|c|}
\hline$<5$ & $1.71 *$ & $1.04-2.83$ \\
\hline $5-9$ & 1.10 & $0.65-1.86$ \\
\hline 10 or more ${ }^{\circledR}$ & 1.00 & \\
\hline \multicolumn{3}{|c|}{ Highest level of education } \\
\hline No education ${ }^{\circledR}$ & 1.00 & \\
\hline Primary & $0.38 * * *$ & $0.22-0.67$ \\
\hline Secondary & $0.27 * * * *$ & $0.14-0.51$ \\
\hline Tertiary & $0.14 * * * *$ & $0.05-0.34$ \\
\hline \multicolumn{3}{|c|}{ Occupation of respondent } \\
\hline Unemployed $^{\circledR}$ & 1.00 & \\
\hline Trading & 0.61 & $0.32-1.18$ \\
\hline Government sector & 1.08 & $0.51-2.29$ \\
\hline Teaching & 1.44 & $0.52-3.93$ \\
\hline Student & $0.40^{*}$ & $0.16-0.99$ \\
\hline Domestic worker & 0.60 & $0.31-1.13$ \\
\hline \multicolumn{3}{|l|}{ Partner occupation } \\
\hline Unemployed $\left.^{(}\right)$ & 1.00 & \\
\hline Agriculture & $6.04 * *$ & $1.68-21.69$ \\
\hline Trading & 1.44 & $0.59-3.44$ \\
\hline Government sector & 1.36 & $0.98-2.26$ \\
\hline Teaching & 2.66 & $0.99-7.14$ \\
\hline Miner & $2.76^{* *}$ & $1.03-7.42$ \\
\hline Casual labour & 1.45 & $0.51-4.18$ \\
\hline
\end{tabular}

Perception of risk of contracting STIs

$\begin{array}{lll}\text { Likely/high } & 1.42 & 0.81-2.48 \\ \text { Unlikely/low } & 2.85^{* * * *} & 1.74-4.67 \\ \text { None }^{\circledR} & 1.00 & \end{array}$

Reasons for risky sexual behaviour

Pleasure $1.72 *$

$1.10-2.72$

Childbearing $^{\circledR} \quad 1.00$

Knowledge that sexual behaviour can affect health

Yes $0.52 * * * \quad 0.33-0.83$

No/don't know ${ }^{\circledR}$

1.00

Belief that partner has right to use force to obtain sex

$\mathrm{Yes}^{\circledR} \quad 1.00$

No 1.90 ***

$1.25-2.90$

Partner's willingness to use condoms

Yes $^{\circledR} \quad 1.00$

No $1.55^{* * * *} \quad 0.36-0.56$ 
that their sexual behaviour could affect their state of health were also significantly $(\mathrm{OR}=0.52, \mathrm{CI}=0.33-0.83)$ less likely to have engaged in a risky sexual act.

\section{Discussion}

Risky sexual behaviour has been in the fore front of public health research since the advent of HIV/AIDS. The research revealed that compared to married and cohabiting adults, young unmarried adults are highly susceptible to risky sexual behaviour (Hoque 2011). However, the increasing prevalence of HIV in marriage (Omanje et al. 2015) indicates that risky sexual behaviour could be prevalent in this group as well. The main objective of this study was therefore to assess the prevalence and identify the predictors of risky sexual behaviour among married and cohabiting women in a setting where HIV is generalized.

Overall, the study found that 4 in 10 married and cohabiting women have ever had a risky sexual act. A number of factors were found to predict risky sexual behaviour by married and cohabiting women in this study. It was found that being married or cohabitating for $<5$ years significantly increased the likelihood of risky sexual behaviour, which is consistent with sexual violence in marriage (Puri et al. 2012). Lack of autonomy on sexual matters and lack of appropriate knowledge and information regarding safe sex have been identified as some of the causes of risky sexual behaviour by women in nascent marriages (Santhya and Jejeebhoy 2005). Additionally, many women in recent marriages are also young in age, often in arranged or imposed marriages and are unaware of sexual and marriage matters and therefore easily sexually abused. Women also experience a decline in marital quality after the first year of marriage and lose interest in sex if they become incompatible with their partners leading to sexual violence and risky sexual behaviour that increases their risk of STIs.

Women whose partners work in agriculture and mining sectors were significantly more likely to have engaged in risky sexual behaviour. Many men who work in the agriculture and mining sectors are periodically away from their wives for extended periods, which make them susceptible to risky sexual behaviours. For example, the poor living conditions of workers and alcohol abuse in commercial agriculture and mining sectors increase the risk of contracting STIs by men who then pass these to their wives on their return home. The finding on the effect of the agriculture sector is consistent with a previous study which found that transactional sex is widespread in commercial agriculture with most men having sex without condoms (Crush 2000). The higher level of exposure to risky sex by wives of mine workers is also consistent with another study that found a high prevalence of HIV in the mining sector in South Africa (Hurkchand et al. 2005) which was blamed on overcrowding in single roomed hostels where sex with commercial sex workers is widespread. The migratory nature of the agriculture and mining sectors and the associated sexual adaptations by men seriously expose women to risky sexual behaviour and STIs every time the men returned home.

The study also found that women who perceived they are unlikely to contract STIs were significantly more likely to have engaged in risky sexual behaviour. This 
is because individuals who perceive themselves at low risk of STIs are unlikely to adopt STI prevention behaviours. This line of thought is consistent with a study which found that individuals who perceived their risk of HIV infection to be low had multiple sexual partners (Nunn et al. 2011). In the case of the women in this study, uptake of safe sex methods may be considered unnecessary because of the belief that a stable relationship protects them from STIs. An earlier study found that women in stable unions resent adoption of safe sex methods either because of perceived partner faithfulness or powerlessness in negotiating safe sex (AwusaboAsare et al. 1993).

Furthermore, the study found that women who engaged in sex to achieve motherhood are more at risk of engaging in risky sexual behaviour. This finding is consistent with the view that some women engage in risky sexual acts out of desperation to achieve motherhood. It is also likely that women are under pressure by their partners and in-laws to give them children, which may force them to engage in unprotected sex even when they know their partner has a STI such as HIV (Wekesa and Coast 2014). Cultural values of most patriarchal societies in subSaharan Africa including South Africa regard childbearing as the primary purpose of marriage and therefore are prioritized regardless of STI status (Dyer et al. 2004). In these societies, children bring honour, status and security to married women. In South Africa proof of motherhood before marriage is not unusual and many women give birth before they are formerly married.

The finding on the perception that men have the right to use force to obtain sex from their wives suggests that culturally inculcated male dominance is a risk factor for susceptibility of women to risky sexual behaviour and STIs. This view has been supported by an earlier study by Isiugo-Abanihe (1994) who found that women believe men have "unlimited" rights to sex. The finding is also consistent with the pervasiveness of sexual violence which is exacerbated by alcohol and drug use in South Africa (Sawyer-Kurian et al. 2009), where it is founded on the belief by some men that having sex with wives is an entitlement. The finding is also consistent with a study in Botswana and Swaziland, which attributed women's proneness to risky sexual behaviour to gender inequality in sexual decisions (Shannon et al. 2012). In societies where gender inequality is pervasive, safer sex practices are untenable mainly because women are socialized to be submissive to their partners and not to challenge cultural sexual norms.

Furthermore, our study revealed that women who reported that their husbands are unwilling to use condoms are likely to have experienced risky sexual behaviour. Men resist use of condoms for a variety of reasons including reduced sexual pleasure and virility; to achieve men's fertility desires; because of the perceived negative risk of STIs in sex with wives; and to show faithfulness to their wives. Therefore, for most men, the condom may be welcome when having transactional sex, but not at home with wives. As a result, wives whose partners engage in risky sexual behaviour, engage in risky sex. The problem is that most of these women are powerless to institute safer sex measures for fear of being blamed for infidelity and the stigma of being accused of having a STI such as HIV (Simbayi et al. 2007).

As expected, we found that education significantly reduced risky sexual behaviour, which is consistent with previous studies. A study in Kenya attributed 
the low prevalence of risky sex among educated people to older age at sexual debut, exposure to and uptake of condom usage and learned life and social skills (Adamczyk and Greif 2011). Education also increases the ability and confidence to discuss sexual matters freely with peers, parents and sexual partners which could help people receive support that has a lifelong effect on their sexual behaviour. However, the finding of this and other studies is contradicted by a few others. For example, a study in South Africa by Tenkorang et al. (2011) found that education is associated with increased risky sexual behaviour due to the Elkind's social recognition theory effects (Alberts et al. 2007) which suggest that educated people believe they know all the risks, do not perceive that they are at any risk or they are equal to the risks associated with their risky sexual behaviour.

Our study also found that women students were less likely to engage in risky sexual behaviour which agrees with another study in Hong Kong (Yip et al. 2013) but is in contrast with another study in Brazil (Sanchez et al. 2013). The study in Hong Kong attributed the lower risky sexual behaviour to outreach sex education programmes to prevent STIs and HIV transmission. In Brazil, risky sexual behaviour by students was explained by the use of alcohol, illicit drugs and casual sex by female students in the poorer socioeconomic group. The lower likelihood of risky sexual behaviour by the students in this study can be attributed to the sex education and HIV prevention programmes in schools that may have equipped students with life and social skills that reinforced protective sexual attitudes and behaviour. However, the gains so far achieved in this regard could be jeopardized by the amendment to the sexual and other related offences act which legalized consensual sex among adolescents as young as 12 years of age by the South African Legislative Assembly in 2015 (Department of Justice 2015).

\section{Limitations}

The study had some limitations that may have affected the results. The first is social desirability bias due to questions on sexual behaviour which are sensitive and private. The second is limitation associated with the sample for the study whose STIs status and that of their partners was unknown. The third limitation is the selfreporting of data by the respondents which may portray the attitudes and behaviours of others and not that of the respondent. The fourth limitation is the use of crosssectional study design which was not able to establish a causal relationship between risky sexual behaviour and the explanatory variables. Nevertheless, the research questions were adapted from previously used instruments in similar studies, which we believe minimized the extent of the limitations on our findings.

\section{Conclusion}

The result of the study suggests that risky sexual behaviour by married and cohabiting women is common in the study area. This is attributed to sexual beliefs and the lack of control of sexual behaviour of men. Many of the arguments used to 
illustrate risky sexual behaviour are cultural and structural which women find difficult to navigate through to enhance safer sexual behaviour. These factors include the short duration of marriage of $<5$ years, partner's occupation which keeps men away from their families for extended periods, desire for motherhood, perceptions that women are unlikely to contract STIs, the believe that partners are culturally entitled to obtain sex if necessary by use of force and unwillingness by some men to use condoms.

The study has contributed important information regarding the predictors of risky sexual behaviours by married and cohabiting women. The results could be used to develop initiatives that can empower women and men through sexual education within the context of marriage and increase the knowledge of women, and exercise of their rights to safe sex through effective participation in sexual decisions. The risky sexual behaviour by women also takes place in the context of fear. Initiatives that reach out to men to change their sexual beliefs, attitudes and behaviour could greatly contribute to reduce the prevalence of risky sexual acts by women and their exposure to STIs and HIV.

Acknowledgments The authors acknowledge the contribution by the Population and Health Research Focus area at North-West University, Mahikeng Campus and the School of Graduate Studies at the Faculty of Human and Social Sciences at Mafikeng Campus for funds used in this study. We also thank the reviewers for the comments and suggestions made to improve the article.

\section{Compliance with Ethical Standards}

Informed Consent All study subjects provided informed consent after explaining to them the aims of the study. Since the questionnaire and in-depth interview guide included sensitive personal questions, participants were informed that the study was voluntary and anonymous. They were also told of their right to refuse answering questions they were not comfortable with or to drop out of the study without consequences. The participants were also assured of the confidentiality of the information they volunteered and the interviews were conducted in private.

Research Involving Human Subjects In accordance with the ethical guidelines for protecting human subjects, research clearance was obtained from the North-West University Research Ethics Committee under number NWU-00048-12-A9.

Open Access This article is distributed under the terms of the Creative Commons Attribution 4.0 International License (http://creativecommons.org/licenses/by/4.0/), which permits unrestricted use, distribution, and reproduction in any medium, provided you give appropriate credit to the original author(s) and the source, provide a link to the Creative Commons license, and indicate if changes were made.

\section{References}

Adamczyk, A., \& Greif, M. (2011). Education and risky sex in Africa: unravelling the link between wome's education and reproductive health behaviours in Kenya. Social Science Research, 40, 654-666.

Agarwal, S., de Araujo, P., \& Jayash, P. (2013). HIV-related knowledge and risky sexual behaviour in sub-Saharan Africa. Oxford Development Studies, 41(2), 173-189. doi:10.1080/13600818.2013. 790950 . 
Alberts, A., Elkind, D., \& Ginsberg, S. (2007). The personal fable and risk-taking in early adolescence. Journal of Youth and Adolescence, 36(1), 71-76.

Anand, A., Shiaishi, R. W., Bennell, R. E., Jacobs, K., Solehdin, N., Abdul-Quader, A. S., \& AberleGrasse, J. M. (2009). Knowledge of HIV status, sexual risk behaviours and contraceptive need among people living with HIV in Kenya and Malawi. Aids, 23, 1565-1573.

Awusabo-Asare, K., Anarfi, J. K., \& Agyeman, D. K. (1993). Women's control over their sexuality and the spread of STDs and HIV/AIDS in Ghana. Health Transition Review, 3, 69-83.

Ayiga, N. (2012). Rates and predictors of consistent condom use by people living with HIV/AIDS on antiretroviral treatment in Uganda. Journal of Health Population and Nutrition, 30(3), 270-280.

Browne, F. A., Wechsberg, W. M., Bowling, J. M., \& Luseno, W. K. (2012). Correlates of male condom use skills among high risk women in South Africa. Journal of Sex Research, 49, 255-263.

Chialepeh, W. N., \& Susuman, A. S. (2015). Risk factors of inconsistent condom use among sexually active youths: Implications for human immunodeficiency virus and sexual risk behaviours in Malawi. Journal of Asian and African Studies. doi:10.1177/0021909615595992.

Crush, J. (2000). Borderline farming: foreign migrants in South African commercial agriculture. Southern African migration project, migration policy series no. 16. (http://www.queensu.ca/samp/ sampresources/samppublications/policyseries/policy16.htm).

Da Walque, D. (2007). Sero-discordant couples in five African countries: Implication for prevention strategies. Population and Development Review, 33, 501-523.

Department of Justice. (2015). Criminal law (sexual offences and related matters) amendment Act No. 5 2015. Republic of South Africa: Cape Town.

Dodoo, F. N. A., \& Frost, A. E. (2008). Gender in African population research: the fertility/reproductive health example. Annual Review of Sociology, 34(1), 431-452.

Dunkle, K. L., Stephanson, R., Karita, E., Chomba, E., Kayitenkore, K., Vwalika, C., \& Allen, S. (2008). New heterosexually transmitted HIV infections in married or cohabiting couples in urban Zambia and Rwanda: An analysis of survey and clinical data. The Lancet, 371, 2183-2191.

Dyer, S. J., Abrahams, N., Makoena, N. E., \& Van der Spuy, Z. M. (2004). You are a man because you have children: experiences, reproductive health knowledge and treatment seeking behaviour among men suffering from couple infertility in South Africa. Human Reproduction, 19, 960-967.

Elisa, T. L., \& Wang, J. (1992). Statistical methods for survival data analyses (2nd ed., pp. 298-314). New York, NY: Wiley.

Falola, T., \& Heaton, M. M. (2007). HIV illness and African wellbeing. Rochester: University Rochester Press.

Gregson, S., Zhuwau, T., Anderson, R. M., Chimbadwa, T., \& Chiwandisa, S. K. (1995). Age and religion selection biases in HIV-1 prevalence data from antenatal clinics in Manicaland, Zimbabwe. The Central African Journal of Medicine, 41, 339-346.

Haberland, N. A. (2015). The case for addressing gender and power in sexuality and HIV education: A comprehensive review of evaluation studies. Guttmacker Institute, 4(3), 311-351.

Hargreaves, J. R., \& Glynn, J. R. (2002). Educational attainment and HIV-1 infection in developing countries: A systematic review. Tropical Medicine \& International Health, 7(6), 489-498. doi:10. 1046/j.1365-3156.2002.00889.x.

Hargreaves, J. R., Morison, L. A., Kim, J. C., Busza, J., Phetla, G., Porter, J. D., \& Pronyk, P. M. (2009). Characteristics sexual partnerships, not just of individuals, are associated with condom use and recent HIV infection in rural South Africa. Aids Care, 21, 1058-1070.

Hoque, M. E. (2011). Reported risky sexual practices amongst female undergraduate students in KwaZulu-Natal, South Africa. African Journal of Primary Health Care and Family Medicine, 3(1), 6. doi:10.4102/phcfm.v3i1.281.

Hurkchand, H., Makuluma, H., Molefe, N., \& Molapo, M. (2005). Measuring the impact of HIV and STIs in a community in a coal mining town, Mpumalanga, South Africa. The Journal of The South African Institute of Mining and Metallurgy, 105, 365-368.

Isiugo-Abanihe, U. C. (1994). Reproductive motivation and family size preferences among Nigerian men. Studies in Family Planning, 25(3), 149-161.

Jones, D., Bagga, R., Nehra, R., Sethi, S., Walia, K., Kumar, M., \& Weiss, S. M. (2013). Reducing sexual risk behaviour among high risk couples in Northern India. International Journal of Behavioural Medicine, 20, 344-354.

Kroska, A., \& Elman, C. (2009). Change in attitudes about employed mothers: exposure, interests and gender ideology discrepancies. Social Science Research, 38, 366-382. 
Langeni, T. T. (2007). Gender power imbalance on women's capacity to negotiate self-protection against HIV/AIDS in Botswana and South Africa. African Health Sciences, 5, 188-197.

Miller, C. L., Bangsberg, D. R., Tuller, D. M., Senkungu, J., Kawuma, A., Frongillo, E. A., \& Weiser, S. D. (2011). Food security and sexual risk in an HIV endemic community in Uganda. Aids and Behaviour, 15, 1512-1819.

Nunn, A., Zaller, N., Cornwall, A., Mayer, K. H., Moore, E., Dickman, S. A. B., et al. (2011). Low perceived risk and high HIV prevalence among a predominantly African American population participating in Philadelphia's rapid HIV testing program. AIDS Patient Care and STDs, 25(4), 229-235.

Omanje, T. S., Bosire, S., \& Mwenda, S. (2015). Knowledge and perceptions of HIV/AIDS among married couples in Kenya. Public Health Research. doi:10.5923/j.phr.20150503.02.

Osuafor, G. N., \& Mturi, A. J. (2014). Attitudes towards sexual control within conjugal union in the era of the HIV/AIDS epidemic in Mahikeng, South Africa. African Population Studies, 28(1), 538-550.

Puri, M., Frost, M., Tamang, J., Lamichhane, P., \& Shah, I. (2012). The prevalence and determinants of sexual violence against young married women by husbands in rural Nepal. BMC Research Notes, 5 , 291. doi:10.1186/1756-0500-5-291.

Sanchez, Z. M., Nappo, S. A., Cruz, J. I., Carlini, E. A., Carlini, C. M., \& Martins, S. S. (2013). Sexual behaviour among high school students in Brazil: alcohol consumption and legal and illegal drug use associated with unprotected sex. Clinics, 68(4), 489-494.

Santhya, K. G., \& Jejeebhoy, S. (2005). Young women's experiences of forced sex within marriage: evidence from India. In S. Jejeebhoy, I. Shah, \& S. Thapa (Eds.), Sex without consent: Young people in developing countries. New York: Zed Books.

Sawyer-Kurian, K. M., Wechsberg, W. M., \& Luseno, W. K. (2009). Exploring the differences and similarities between black/African and coloured men regarding violence against women, substance abuse and HIV risk in Cape Town, South Africa. Psychology of Men and Masculinity, 10(1), 13-29.

Scott, S. (2010). HIV/AIDS: Understanding socio-cultural factors and their influence on sexual behaviour and decision making in Africa. Journal of the University of Manitoba Anthropology Student Association, 28, 83-93.

Shannon, K., Leiter, K., Phladze, N., Hlanza, Z., Tsai, C., Heisler, M., \& Weiser, S. D. (2012). Gender inequality norms are associated with increased male perpetrated rape and sexual risks for HIV infection in Botswana and Swaziland. Plos One, 7, e28739.

Shisana, O. (2005). South African national HIV prevalence, HIV incidence, behaviour and communication survey, 2005. Cape Town: HSRC press.

Simbayi, L. C., Kalichman, S. C., Strebel, A., Cloete, A., Henda, N., \& Mqeketo, A. (2007). Disclosure of HIV status to sex partners and sexual risk behaviours among HIV-positive men and women, Cape Town, South Africa. Sexual Transmitted Infection, 83, 29-34.

Tenkorang, E. Y., Maticka-Tyandale, E., \& Rajulton, F. (2011). A multi-level analysis of risk perception, poverty and sexual risk taking among young people in Cape Town, South Africa. Health \& place, $17,525-535$.

Van Loggerrenberg, F., Dieter, A. A., Sobieszczyk, M. E., Weiner, L., Grobler, A., Mlisana, K., \& CAPRISA Acute Infection Study Team. (2012). HIV infection in high risk women in South Africa: Condom use and the need for change. Plos One, 7, e30669.

Wekesa, E., \& Coast, E. (2014). Fertility desires among men and women living with HIV/AIDS in Nairobi slums: A mixed methods study. Plos One, 9(8), e106292.

White, P. E., Zondi, M., Mavundla, G., \& Gumede, H. (1990). Teenage pregnancy, whose problem? Realities and prospects for action in KwaZulu-Natal. South African Journal of Demography, 3, 11-20.

Wusu, O., \& Isiugo-Abanihe, U. C. (2010). Understanding sexual negotiation between married partners: A study of the Ogu families in South Western Nigeria. African Population Studies, 23, 151-171.

Yip, P. S., Zhang, H., Lam, T. H., Lam, K. F., Lee, A. M., Chan, J., \& Fan, S. (2013). Sex, knowledge, attitudes and high risk sexual behaviours among unmarried youth in Hong Kong. BMC Public Health, 13(1), 691. 